\title{
Knowledge and Awareness of Parents Toward Thalassemia
}

Tanuka Barua ${ }^{1 *}$

Dazy Barua ${ }^{2}$

Dhananjoy Das ${ }^{1}$

Rupam Talukdar ${ }^{2}$

Razia Sultana ${ }^{3}$

Mahmood A. Chowdhury (Arzu) ${ }^{1}$

'Department of Paediatrics

Chattagram Maa-O-Shishu Hospital Medical College Chattogram, Bangladesh.

${ }^{2}$ Department of Paediatrics

Chattogram Medical College

Chattogram, Bangladesh.

${ }^{3}$ Department of Pathology

Chattagram Maa-O-Shishu Hospital Medical College

Chattogram, Bangladesh.
${ }^{*}$ Correspondence to:

Dr Tanuka Barua

Associate Prosessor

Department of Paediatrics

Chattogram Maa-O-Shishu Hospital Medical College

Chattogram, Bangladesh.

Mobile : +8801821654937

Email : tanukadr@gmail.com

Date of Submission ： 22.11 .2020

Date of Acceptance : 05.01 .2021

www.banglajol.info/index.php/CMOSHMCJ

\begin{abstract}
Background: Thalassemias are the most common heritable blood disorders that represents a major public concern. Poor awareness and lack of knowledge lead to increase number of carrier that is a silent reservoir of the disease. To observe the knowledge and awareness level of parents of thalassemic children about the disease.
\end{abstract}

Materials and methods: This descriptive cross-sectional study was conducted in the Thalassemia ward of Chattogram Maa Shishu-O-General Hospital, Chattogram from July 2013 to June, 2014. Parents of 70 thalassemia patients aged 2-18 years interviewed with a formulated questionnaire based on knowledge status and awareness level of parents towards thalassemia. Data were analyzed by both manually and by SPSS-18.

Results: Majority of patients were from rural background (54.3\%). Only $8.6 \%$ parents were consanguineous parents and majority of them completed only secondary education. $44.3 \%$ resolved it as inherited disorder. $52.9 \%$ resolved thalassemia cannot be cured. Only 24.3\% regarded bone marrow transplantation as a measure of cure. More than half (55.7\%) did not know how to prevent thalassemia. Only 37.1\% knew about prenatal diagnosis. Carrier status of both father and mother were unknown in majority of patients (80\%) and screening of sibs was not done at all in a significant number of patients (51.5\%). Only 34.3\% wanted to do prenatal diagnosis after conception and $65.7 \%$ parents were ready to accept therapeutic abortion if fetus would be diagnosed as thalassemia by prenatal diagnosis.

Conclusion: Knowledge level and awareness of parents of thalassemic child regarding the disease is unsatisfactory. To reduce disease burden an awareness program regarding the disease and its prevention covering premarital screening, acceptance of prenatal diagnosis and therapeutic abortion is essential.

Key words: Thalassemia; Knowledge level; Awareness level.

\section{INTRODUCTION}

Thalassemia is the most common hemoglobin disorder in the world. It has emerge as a huge public health problem worldwide ${ }^{1}$. About $1.5 \%$ of the global population are carrier of beta thalassemia with about 60,000 symptomatic individual born annually with great majority in the developing world ${ }^{2,3}$. Thalassemia is becoming a burden for our country. A conservative WHO report estimates that $3 \%$ of total population is carrier of $\beta$-thalassemia and $4 \%$ are carriers of $\mathrm{Hb} \mathrm{E}$ disease in Bangladesh and more than two thousand thalassemic children are born every year ${ }^{4,5}$.

The most effective approach to reduce the burden to society and the disease incidence is implementation of carrier screening program, genetic counseling, prenatal 
diagnosis and selective termination of affected foetus ${ }^{6}$. Poor awareness, lack of information about inheritance pattern has led to an increased number of patients ${ }^{7}$. Some socio-cultural barrier for screening and superstition regarding inheritance also plays a great role. Still, premarital testing is not accepted in some countries for various legal and cultural factors ${ }^{8}$. Knowledge of parents regarding thalassemia is crucial for understanding of the disease and thereby to prevent the disease. Inadequate knowledge about thalassemia results in continue sufferings of patients in a slow and painful course ultimately leading to death ${ }^{9}$. The only way to prevent the disease and reduce the morbidity and mortality is by educating the general population ${ }^{10}$. Fortunately, awareness level is improved significantly worldwide ${ }^{11,12}$. Effectiveness of a prevention program can result in significant reduction of birth rate of thalassemia ${ }^{13}$. There have been no large epidemiological studies to provide a true picture of screening practice and awareness of parents towards future pregnancy.

Studies on knowledge and awareness regarding thalassaemia are relatively scarce in Bangladesh. This study was conducted to assess the knowlege and awareness level of parents of thalassemia patients by which we can provide valuable message to national planning and health policy and also to non-governmental organization to take necessary steps with more emphasis on improvement of public awareness and thereby prevention of the disease

\section{MATERIALS AND METHODS}

It was a descriptive cross-sectional study conducted at the Thalassemia ward of Chattogram Maa Shishu-O-General Hospital, Chattogram from July 2013 to June 2014. Parents of 70 thalassaemia patients aged 2-18 years attending Thalassaemia Care Centre of Chattogram Maa Shishu-O-General Hospital, Chattogram were included in this study. After approval from the Ethical Review Committee of Chattogram Maa Shishu-O-General Hospital, Chattogram, informed written consent was obtained from any of parents or a family member of each patient. Detailed study related information was read out and explained in the local language from a printed hand out. Parents were interviewed according to a formulated questionnaire asking about inheritance pattern, preventive measure, prenatal diagnosis, screening of family member, acceptance of therapeutic abortion etc. Data were recorded and analyzed manually with the help of calculator and software SPSS 18.0.

\section{RESULTS}

Majority of patients (54.3\%) were from rural background. Only $8.6 \%$ parents were non-consanguine. Most of the parents (fathers $=51.5 \%$, mothers $=48.6 \%$ ) were up to secondary level education. $10 \%$ fathers and $20 \%$ mothers did not go to school ever. Only $21.4 \%$ fathers $10 \%$ mothers were graduate and above (Table I).
Table I : Parent's demographics $(\mathrm{n}=70)$.

$\begin{array}{lrc}\text { Variables } & \text { Frequency } & \text { Percentage (\%) } \\ \text { Locality } & & \\ \text { Rural } & 38 & 54.3 \\ \text { Urban } & 32 & 45.7 \\ \text { Consanguineous parents } & & \\ \text { Yes } & 6 & 8.6 \\ \text { No } & 64 & 91.4 \\ \text { Parent's education (Father) } & & \\ \text { Nil } & 7 & 10.0 \\ \text { Primary } & 2 & 2.8 \\ \text { Secondary } & 36 & 51.5 \\ \text { Higher Secondary / College } & 10 & 14.3 \\ \text { Graduate \& Above } & 15 & 21.4 \\ \text { Parent's education (Mother) } & & \\ \text { Nil } & 14 & 20.0 \\ \text { Primary } & 8 & 11.4 \\ \text { Secondary } & 34 & 48.6 \\ \text { Higher Secondary / College } & 7 & 10.0 \\ \text { Graduate \& Above } & 7 & 10.0\end{array}$

Only $44.3 \%$ resolved thalassemia as inherited disorder and $21.4 \%$ did not have any knowledge though they have thalassemic child. $52.9 \%$ considered that thalassemia cannot be cured and $24.3 \%$ regarded bone marrow transplantation as a measure of cure. Only $44.3 \%$ have knowledge that thalassemia can be prevented and more than half parents $(55.7 \%)$ did not know how to prevent thalassemia. Only $37.1 \%$ knew about prenatal diagnosis. (Table II) So knowledge of parents regarding thalassemia disease was quite low though they had a thalassemic child.

Table II : Knowledge of parent's regarding thalassemia $(\mathrm{n}=70)$.

Knowledge Number Percentage (\%)

$\begin{array}{lrr}\text { Thalassemia is a: } & & \\ \text { Inherited Disease } & 31 & 44.3 \\ \text { Blood Disease } & 24 & 34.3 \\ \text { Does Not Know } & 15 & 21.4 \\ \text { It can be cured: } & & \\ \text { Yes } & 19 & 27.1 \\ \text { No } & 37 & 52.9 \\ \text { Does Not Know } & 14 & 20.0 \\ \text { How can it be cured: } & & \\ \text { By bone marrow transplantation } & 17 & 24.3 \\ \text { By blood transfusion } & 2 & 2.8 \\ \text { Does Not Know } & 51 & 72.9 \\ \text { It can be prevented: } & & \\ \text { Yes } & 31 & 44.3 \\ \text { No } & 15 & 21.4 \\ \text { Does Not Know } & 24 & 34.3 \\ \text { How can it be prevented: } & & \\ \text { Avoidance of marriage of carriers } & 30 & 42.9 \\ \text { By blood transfusion } & 1 & 1.4 \\ \text { Does Not Know } & 39 & 55.7 \\ \text { Know about prenatal diagnosis: } & & \\ \text { Yes } & 26 & 37.1 \\ \text { No } & 44 & 62.9\end{array}$


In $80 \%$ cases, carrier status of both father and mother were unknown. In more than half families $(51.5 \%)$ screening of siblings was not done at all. About $34.3 \%$ parents wanted to do prenatal diagnosis in future pregnancy and $65.7 \%$ parents were ready to accept therapeutic abortion if fetus would be diagnosed as thalassemia by prenatal diagnosis. Cent percent parents showed good awareness by making their child vaccinated against Hepatitis B viruses who were not vaccinated against Hepatitis B infection under EPI schedule. (Table III) But considering all the parameter we can say awareness of parents of thalassemic child was not satisfactory.

Table III : Awareness of parent's regarding thalassemia $(\mathrm{n}=70)$.

$\begin{array}{lrr}\text { Awareness } & \text { Number } & \text { Percentage (\%) } \\ \text { Screening of parents: } & 56 & \\ \text { Both not done } & 11 & 15.0 \\ \text { Both done } & 0 & 0.0 \\ \text { Father carrier, Mother not done } & 3 & 4.3 \\ \text { Mother carrier, Father not done } & & \\ \text { Screening of sibling: } & 36 & 51.5 \\ \text { Not done } & 15 & 21.4 \\ \text { All done } & 4 & 5.7 \\ \text { One sib done, other not done } & 15 & 21.4 \\ \text { No sib } & & \\ \text { Hepatitis B vaccine coverage of patients: } & 100.0 \\ \text { Yes } & 70 & 0.0 \\ \text { No } & 0 & \\ \text { Plan for next baby: } & & 44.3 \\ \text { Don't want to conceive } & 31 & 34.3 \\ \text { Want to do prenatal diagnosis } & 24 & 21.4 \\ \text { Not decided } & 15 & \\ \text { Will accept therapeutic abortion if confirmed } & & 65.7 \\ \text { about affected fetus by prenatal diagnosis: } & & 22.9 \\ \text { Yes } & 46 & 11.4 \\ \text { No } & 16 & \\ \text { Not decided } & 8 & \end{array}$

\section{DISCUSSION}

Similar to Mallik S et al majority of our patients were from rural background ( 54.3\%) implies that rural health care center in our country are not yet developed up to that level for blood transfusion, cross matching etc so that patients had to come to the city that is sometimes at a long distance from rural area ${ }^{14}$. Facilities for safe blood transfusion, cross matching should be available at the nearest health care center and decentralization of blood screening facility should be organized.

$8.6 \%$ of our parents were consanguineous parents, the rest others were unknown to each other before marriage whereas in Pakistan 56.9\% patient's parents were first cousin, 19.4\% parents were also relative and only $23.7 \%$ were unknown to each other ${ }^{15}$. The consanguinity rate were also higher $(50.9 \%)$ in $\operatorname{Iran}^{16}$. Our findings indicate that though consanguineous parents is a risk group for thalassemia, a large number of parents being non-consanguineous is prevailing in our society as a silent carrier indicating importance of screening of all couple should be mandatory irrespective of consanguineous or not.

Educational status of majority of our parents (Father $=51.5 \%$, mother $=48.6 \%$ ) were up to secondary level, similar results also reported in Kolkata, Pakistan ${ }^{14,17,18}$. 10\% fathers and 20\% mothers of our study did not go to school ever in their life whereas $66.7 \%$ and $78.1 \%$ parents were illiterate in different places of Pakistan ${ }^{9,15}$. In contrast only $3.5 \%$ parents were illiterate in $\operatorname{Iran}^{19}$. Only $21.4 \%$ fathers and $10 \%$ mothers were graduate or above in our study. Educational level of parents were found better in Foisalabad and Mumbai ${ }^{18,20}$.

Regarding knowledge level of parents about thalassemia, we highlighted the conception about inheritance pattern of thalassemia, knowledge about cure and prevention. $44.3 \%$ parents of our study considered thalassemia as inherited disease whereas $15 \%$ parents in Pakistan and $68.9 \%$ in Kolkata considered thalassemia as an inherited disorder ${ }^{9}, 14.27 .1 \%$ of our parents told that it can be cured and only $24.3 \%$ mentioned bone marrow transplantation as a measure of cure indicating poor knowledge level. In contrast, only $14.7 \%$ had good knowledge about thalassemia in $\operatorname{Iran}^{16}$. It is obvious that more patients aware of prevention $(44.3 \%)$ than those aware of cure $(27.1 \%)$ which is good for social awareness for prevention though the percentage is quite lower than that of Kolkata where $60.7 \%$ knew how to prevent thalassemia ${ }^{14}$. About $37.1 \%$ our parents knew about prenatal diagnosis of thalassemia whereas in Pakistan 31.1\% parents were familiar to prenatal diagnosis that is similar to our finding ${ }^{15}$.

Regarding assessment of awareness level of parents towards thalassemia, we found only in $15.7 \% \%$ cases, father and mother both were screened for thalassemia and in $80 \%$, none was screened for thalassemia. But in Kolkata $72 \%$ patients had both parents diagnosed as carrier and only in $17.5 \%$ cases carrier status of both parents was not known ${ }^{14}$. This reflects that awareness level of our parents in regards to prevention of disease is still quite low in our country. Screening of all other sibs was done in only $21.4 \%$ cases and in $51.5 \%$, it was not done at all reflecting that screening practice is also not satisfactory. But in a study of Arif $\mathrm{F}$ et al only $5.8 \%$ parents had the sibling screened $^{9}$. It may be related to educational status, religious beliefs and financial condition of parents. In contrast to that study where only $12.5 \%$ were immunized against Hepatitis B, all the patients of our study were vaccinated against Hepatitis B virus suggesting good awareness of parents regarding transfusion transmitted infection ${ }^{9}$. About $44.3 \%$ of our parents did not want to conceive in future and want to adopt some form of family planning method whereas in Kolkata, Mumbai it is about $51.8 \%$ and $73 \%$ respectively ${ }^{14,20}$. In Pakistan $70.9 \%$ parents were against family planning method due to religious matter and other constrained ${ }^{15}$. This is a message of hope that despite social and religious superstition prevailing in our society, a good percentage of our parents (34.3\%) were aware of disease 
burden and wanted to do prenatal diagnosis for future pregnancy and $65.7 \%$ would accept therapeutic abortion if fetus is prenatally diagnosed as thalassemia whereas in Pakistan and in Canada $18.1 \%$ and $31 \%$ parents respectively accepted it for affected fetus in future pregnancy ${ }^{15,21}$. Besides screening for carrier detection of parents and siblings, prevention plan for next baby depends on awareness which is contributed by educational status of parents.

\section{LIMITATIONS}

- This was a cross-sectional study where only 70 patients were included

- Limited period of study for one year only

- Data were collected only from one hospital.

\section{CONCLUSION}

We observed that knowledge of the parents regarding thalassemia is still poor and awareness level of parents regarding screening for carrier identification, prevention of thalassemia is also not satisfactory. An educational intervention program may be effective to provide families with full medical information to help them have healthy children and to reduce social burden to ensure a social, economic and less painful life to them. The most effective approach to reduce the burden to society is implementation of a carrier screening program. Health policy makers should undertake awareness program and antenatal screening program and pre-marital screening towards prevention of thalassemia should be made mandatory before wedding and that should be enforced by law. We did not correlate our findings with the educational status and social background of parents. There are several areas regarding this that could impact on future research and practice.

\section{DISCLOSURE}

All the authors declared no competing interest.

\section{REFERENCES}

1. Weatherall DJ, Clegg JB. Thalassemia is a global public health problem. NatMed. 1996;2:846-849.

2. Colah R, Gorakshakor A, Nadkarni A. Global burden, distribution and prevention of beta-thalassemia and hemoglobin E disorders. Expert Rev Hematol. 2010;3(1):103-117.

3. Galanello R and Origa R. Review: Beta-thalassemia. http://www.ojrd.com/content/5/1/11, published - (Accessed on 21 May, 2010)

4. WHO guidelines for control of hemoglobin disorders. Unpublished document WHO/HDP/HB/GL/94.

5. $\quad$ Khan WA. Thalassemia in Bangladesh. Dhaka Shishu (Child) Hospital Journal. 1999;15:42-44.

6. Angastiniotis M, Modell B. Global epidemiology of hemoglobin disorders. Ann NY Acad Sci. 1998;850:251-269.

7. Scriver CR, Bardonis M, Cartier L, Clow CL, Lancarter GA, Ostrosky JT. Beta-thalassemia disease prevention: Genetic medicine applied. Am J Hum Genet. 1984;36:1024-1038.

8. Heghpanah S, Nasirabadi S, Rahimi N, Faramarzi H, Karimi M. Socio-cultural challenges of beta-thalassemia major birth in carriers of betathalassemia in Iran. J Med Screen. 2012;19(3):109-111.

9. Arif F, Fayyaz J, Hamid A. Awareness among parents of children with thalassemia major. JPMA. 2008;58(11):621-624.

10. Hassan K, Aslam M, Ikram N. Parental knowledge and awareness in cases of thalassemia major. J Pak Inst Med Sci. 2002; 13: 623-626.

11. Rosu M. One step forward in health promotion. J Med Life. 2012;5(3):367-372.

12. Berdoykas V, Farmaki K, Carson S, Wood J, Coates T. Treating thalassemia major related iron overload: the role of deferiprone. J Blood Med. 2012;3:119-129.

13. Cao A, Rosatelli MC, Galanello R. Control of beta-thalassemia by carrier screening, genetic counseling and prenatal diagnosis: The Sardanian experience. Ciba Found Symp. 1996;197:137-151.

14. Mallik S, Chatterjee C, Mandal PK, Sardar JC, Ghosh P and Manna N. Expenditure to treat thalassemia: An experience at a tertiary care hospital in India. Iran J Public Health. 2010;39(1):78-84.

15. Qumruzzaman and Salahuddin. Association between the education and thalassemia : A statistical study. Pak J Stat Oper Res. 2006;11(2):103-110

16. Ebrahim MM, Eisa M, Leila E, Alireza D, Marziyeh H. High school knowledge and attitudes towards thalassemia in South-eastern Iran. Int J Hematol Oncol Stem Cell Res. 2014;8(1):24-31.

17. Bandyopadhyay B, Nandi S, Mitra K, Mandal PK, Mukhopadhayay S, Biswas AB. Comparative study on perceptions and practices among parents of thalassemic children attending two different institutions. Ind Medica. 2003;28(3) (Copyright @ 2005 Indomedica).

18. Rahaman S, Batool S, Qadir R. Socio economic status impact thalassemia child on families of Faisalabad district. Pak J of Appl Sci. 2002;2(2):202-205

19. Sattari MR, Shoykhi D, Nikanfur A, Pourfeizi AH, Nanari M, Dolatkhah R et al. The finantial and social impact of thalassemia and $1^{\text {st }}$ treatment in Iran. Pharma Sci. 2012;18(3):171-176.

20. Sangani B, Sukumaran PK, Mahadik C. Thalassemia in Bombay: Role of medical genetics in developing countries. Bulletin. 1990;68(1):75-81.

21. Ostrowsky JT, Lippman A, Scriver CR. Cost-benefit analysis of a thalassemia disease prevention program. Am J Public Health. 1985;75:732-736. 